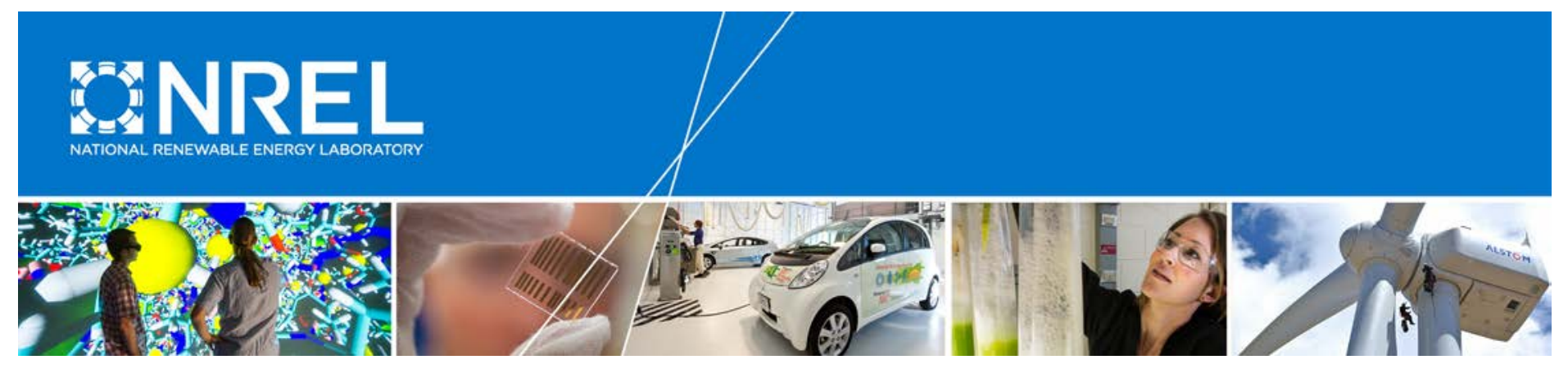

\title{
Dynamic Braking System of a Tidal Generator
}

\section{Preprint}

\author{
Eduard Muljadi, Alan Wright, \\ and Vahan Gevorgian \\ National Renewable Energy Laboratory \\ James Donegan, Cian Marnagh, \\ and Jarlath McEntee \\ Ocean Renewable Power Company
}

To be presented at the 2016 IEEE Energy Conversion Congress and Exposition

Milwaukee, Wisconsin

September 18-22, 2016

(C) 2016 IEEE. Personal use of this material is permitted. Permission from IEEE must be obtained for all other uses, in any current or future media, including reprinting/republishing this material for advertising or promotional purposes, creating new collective works, for resale or redistribution to servers or lists, or reuse of any copyrighted component of this work in other works.

NREL is a national laboratory of the U.S. Department of Energy Office of Energy Efficiency \& Renewable Energy Operated by the Alliance for Sustainable Energy, LLC

This report is available at no cost from the National Renewable Energy Laboratory (NREL) at www.nrel.gov/publications.

\section{Conference Paper}

NREL/CP-5D00-66396

August 2016

Contract No. DE-AC36-08G028308 


\section{NOTICE}

The submitted manuscript has been offered by an employee of the Alliance for Sustainable Energy, LLC (Alliance), a contractor of the US Government under Contract No. DE-AC36-08GO28308. Accordingly, the US Government and Alliance retain a nonexclusive royalty-free license to publish or reproduce the published form of this contribution, or allow others to do so, for US Government purposes.

This report was prepared as an account of work sponsored by an agency of the United States government. Neither the United States government nor any agency thereof, nor any of their employees, makes any warranty, express or implied, or assumes any legal liability or responsibility for the accuracy, completeness, or usefulness of any information, apparatus, product, or process disclosed, or represents that its use would not infringe privately owned rights. Reference herein to any specific commercial product, process, or service by trade name, trademark, manufacturer, or otherwise does not necessarily constitute or imply its endorsement, recommendation, or favoring by the United States government or any agency thereof. The views and opinions of authors expressed herein do not necessarily state or reflect those of the United States government or any agency thereof.

This report is available at no cost from the National Renewable Energy Laboratory (NREL) at www.nrel.gov/publications.

Available electronically at SciTech Connect http:/www.osti.gov/scitech

Available for a processing fee to U.S. Department of Energy and its contractors, in paper, from:

U.S. Department of Energy

Office of Scientific and Technical Information

P.O. Box 62

Oak Ridge, TN 37831-0062

OSTI http://www.osti.gov

Phone: 865.576.8401

Fax: 865.576.5728

Email: reports@osti.gov

Available for sale to the public, in paper, from:

U.S. Department of Commerce

National Technical Information Service

5301 Shawnee Road

Alexandria, VA 22312

NTIS http://www.ntis.gov

Phone: 800.553 .6847 or 703.605 .6000

Fax: 703.605.6900

Email: orders@ntis.gov 


\title{
Dynamic Braking System of a Tidal Generator
}

\author{
E. Muljadi, Fellow, IEEE, A. Wright, V. Gevorgian, Member, IEEE, \\ J. Donegan, Member, IEEE, C. Marnagh, J. McEntee
}

\begin{abstract}
Renewable energy generation has experienced significant cost reductions during the past decades, and it has become more accepted by the global population. In the beginning, wind generation dominated the development and deployment of renewable energy; however, during recent decades, photovoltaic (PV) generation has grown at a very significant pace due to the tremendous decrease in the cost of PV modules. The focus on renewable energy generation has now expanded to include new types with promising future applications, such as river and tidal generation. The input water flow to these types of resources is more predictable than wind or solar generation.
\end{abstract}

The data used in this paper is representative of a typical river or tidal generator. The analysis is based on a generator with a power rating of $40 \mathrm{~kW}$. The tidal generator under consideration is driven by two sets of helical turbines connected to each side of the generator located in between the turbines. The generator is operated in variable speed, and it is controlled to maximize the energy harvested as well as the operation of the turbine generator. The electrical system consists of a three-phase permanent magnet generator connected to a three-phase passive rectifier. The output of the rectifier is connected to a DC-DC converter to match the rectifier output to the DC bus voltage of the DC-AC inverter. The three-phase inverter is connected to the grid, and it is controlled to provide a good interface with the grid.

One important aspect of river and tidal generation is the braking mechanism. In a tidal generator, the braking mechanism is important to avoid a runaway condition in case the connection to the grid is lost when there is a fault in the lines. A runaway condition may lead to an overspeed condition and cause extreme stresses on the turbine blade structure and eventual disintegration of the mechanical structure. In this paper, the concept of the dynamic braking system is developed and investigated for normal and abnormal operations. The main objective is to optimize the performance under emergency braking while designing the system to be as simple as possible to avoid overdesigning the power electronics or exceeding the target budget.

Index Terms-braking, dynamic model, marine, hydrokinetic, permanent magnet, power plant, river, tidal, synchronous generator, turbine.

\section{INTRODUCTION}

$\mathrm{D}$ URING the past few decades, a significant body of work has been dedicated to wind generation, and as such the nature of the resource is generally well understood. Tidal generation has characteristics similar to wind generation; thus, the knowledge we have acquired about wind generation can be readily transferred to a certain degree to tidal generation. The tidal generator we consider in this paper is very similar to a direct-drive wind generator with full power conversion, also known as a Type 4 wind turbine generator. An overview of marine hydrokinetic generation is given in [1], [2]. Resource assessment of tidal generation can be found in [3]-[5], while the control to maximize energy capture is discussed in [6], [7].

The hydrokinetic prime mover in the power generation is a series of Gorlov hydro turbines connected together as shown in Fig. 1. The two sets of turbines drive the permanent magnet generator in the middle. The generator is controlled by a complete set of power electronics that convert the hydrodynamic power into electrical power. A simplified diagram of the electrical power conversion is shown in Fig. 2. The generator is a direct-drive permanent magnet synchronous generator [8], and a discussion on electro-mechanical braking for a transportation system can be found in [9], [10].

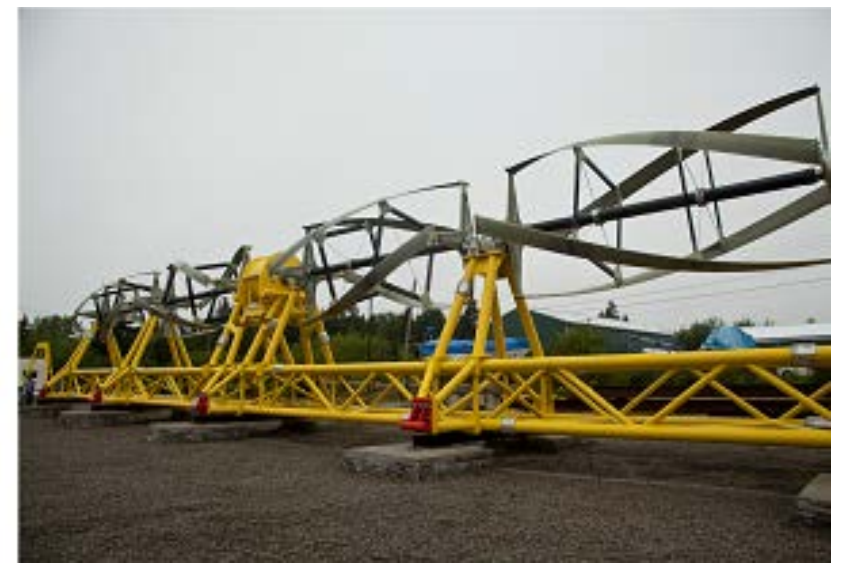

Figure 1. Example tidal generator consisting of a series of connected Gorlov turbines. Image from Wikipedia

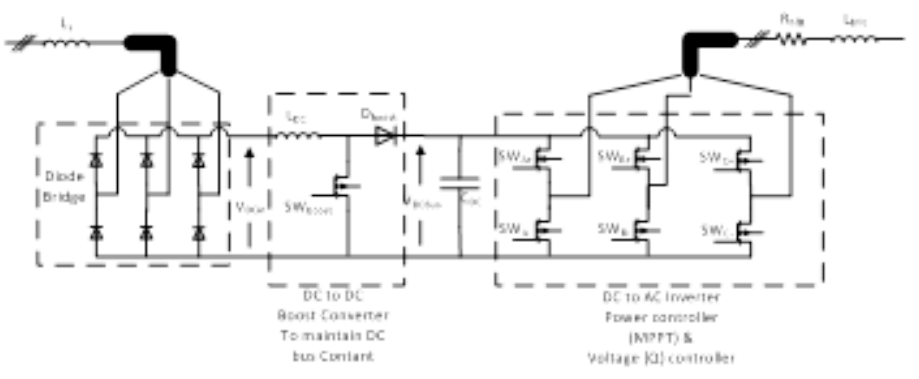

Fig. 2. Simplified diagram of the electrical power conversion

The sequence of this paper will be arranged as follows: Section II presents the concept of the balance of power, Section III discusses the implementation of dynamic braking, and Section IV presents the conclusion. 


\section{BALANCE OF POWER}

The balance of power between the energy source generating the hydrodynamic power and the energy sink absorbing energy in the form of electrical energy (power entering the grid) must be maintained at all times to achieve multiple goals, such as maximizing energy capture, maintaining the mechanical integrity of the structure and components of the generation, and producing good power quality while providing ancillary services to the grid.

In this paper, we focus on the specific task of designing and operating the dynamic braking system of the turbine to avoid a runaway problem.

\section{A. Hydrodynamic Representation}

The available hydrodynamic power of a water turbine can be computed from the water flow and the turbine dimension. The tip speed ratio (TSR) is defined as the ratio of the linear speed of the tip of the blade to the flow speed

$$
\begin{aligned}
& P_{\text {turbine }}=0.5 \rho A C_{p} C_{p} V^{3} \\
& T S R=\frac{\omega R}{V}
\end{aligned}
$$

where $A$ is the cross sectional area of the turbine $[\mathrm{m}], \rho$ is the water density $\left[\mathrm{kg} / \mathrm{m}^{3}\right], \mathrm{V}$ is the speed of the water flow $[\mathrm{m} / \mathrm{s}]$, and $\mathrm{C}_{\mathrm{p}}$ is the performance coefficient of the turbine. The $\mathrm{C}_{\mathrm{p}}$ of the typical turbine of a tidal generator under consideration is available. The rotational speed, $\omega$, is the rotational speed of the blade. The maximum operating $C_{p}\left(C_{p m a x}\right)$ is 0.32 for this turbine and corresponds to $\mathrm{TSR}_{\mathrm{cp} \_ \text {max }}=1.9$.

The equation used to control the generation can be further simplified as shown in (3):

$$
P_{\text {gen }}=K_{\text {Cpmax }} \omega^{3}
$$

where $K_{\text {Cpmax }}=0.5 \rho A C_{\text {pmax }}\left(\frac{R}{T_{\text {mR }} \text { Ppmax }}\right)^{3}$

\section{B. Torque Equations}

The balance of electromechanical power allows the speed to be controlled. The equation governing the speed can be simply expressed as follows:

$$
\omega_{m}=\frac{1}{J} \int\left(T_{m}-T_{e}\right) d t
$$

And:

$$
\begin{aligned}
& T_{m}=\frac{P_{\text {Turbine }}}{\omega_{m}} \\
& T_{e}=\frac{P_{\text {gen }}}{\omega_{m}}
\end{aligned}
$$

where $\omega_{\mathrm{m}}$ is the rotational speed in mechanical radian/second, $\mathrm{T}_{\mathrm{m}}$ is the mechanical torque driving the generator (N.m.), and
$\mathrm{T}_{\mathrm{e}}$ is the electrical torque of the generator (N.m.). Under normal conditions, the electrical torque is controlled to maximize energy capture, thus maximizing the performance coefficient, $\mathrm{C}_{\mathrm{p}}$. On the other hand, to avoid a runaway condition, a sufficient braking torque must be applied to control the rotational speed below the allowable rotational speed limit. Cross flow turbines "runaway condition" is limited to the hydrodynamic maximum TSR for a given flow speed, so as long as the electrical system is rated to allow for this condition, which it should be, then this freewheel state is not a short term is sue.

\section{Electrical Generator Representation}

The permanent magnet generator is basically a voltage source directly proportional to the rotational speed. The terminal of the generator is connected to the DC rectifier; thus, in a per-phase AC equivalent circuit, the DC rectifier can be considered variable resistance, and the size of the effective resistance can be controlled by the power electronic devices.

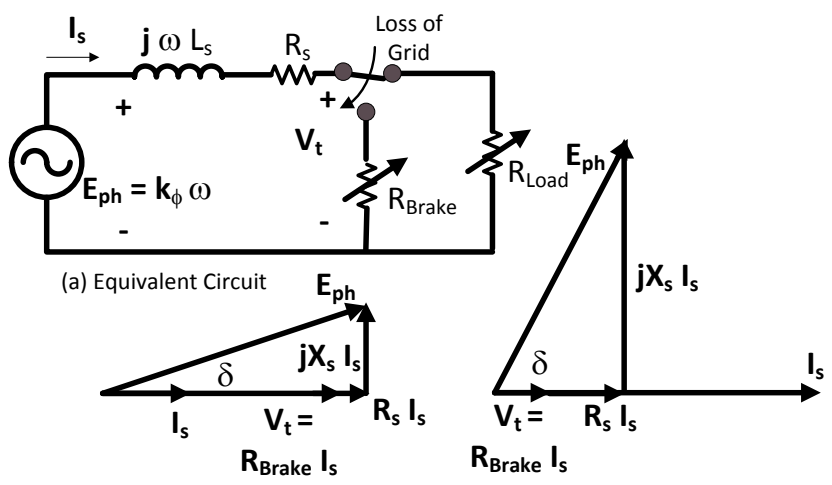

(b) $R_{\text {brake }}$ - Large

(c) $R_{\text {brake }}$ - Small

Fig. 3. Per-phase equivalent circuit and phasor diagrams

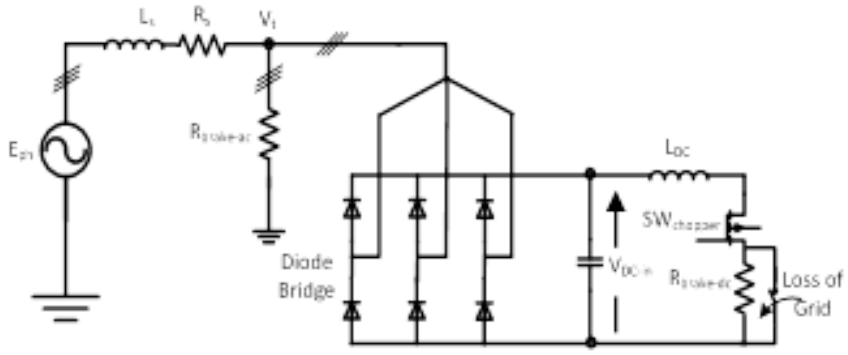

Fig. 4. Implementation of $\mathrm{R}_{\text {brake }}$ with $\mathrm{AC}$ and/or DC resistors

The internal emf $\mathrm{E}$ of the permanent magnet synchronous generator connected to a diode rectifier can be expressed as:

$$
E_{p h}=k_{\Phi} \omega
$$

The frequency of the generator can be expressed as a function of the rotational speed, $\omega_{\mathrm{m}}$ and the number of poles, pole.

$$
\omega=\frac{\text { pole }}{2} \omega_{m}
$$


The terminal voltage can be expressed as in (9). Note that in order to ensure that the electrical current is to flow in the circuit, the magnitude of the internal emf $\mathrm{E}$ must be higher than the magnitude of the voltage $V_{t}\left(E>V_{t}\right)$ :

$$
V_{t}=R_{\text {Load }} I_{s}
$$

And:

$$
\begin{aligned}
& R_{\text {Load }}=\frac{P}{3 I_{s}^{2}} \\
& E_{p h}=V_{t}+R_{s} I_{s}+j \omega L_{s} I_{s}
\end{aligned}
$$

where

$\mathrm{E}_{\mathrm{ph}}=$ per-phase internal emf of the permanent magnet synchronous generator

$\omega=$ electrical frequency in electrical radian/sec

$\mathrm{R}_{\text {Load }}=$ variable resistance representing variable output power $\mathrm{P}$ into a diode bridge and the grid

$\mathrm{V}_{\mathrm{t}}=\mathrm{AC}$ equivalent of the per-phase terminal voltage connected to a rectifier (not drawn)

$\mathrm{I}_{\mathrm{S}}=$ the stator current feeding the rectifier bridge at unity power factor

$\mathrm{L}_{\mathrm{s}}=$ the stator inductance

$\mathrm{R}_{\mathrm{s}}=$ the stator resistance

By controlling the power converter, the output power delivered to the grid can be adjusted. The variable load resistance represents the output power delivered to the grid. Under normal conditions, the stator current is within the normal range (up to the rated current); and the voltage drop across the stator resistance, $R_{s}$, can be neglected $\left(I_{s} R_{s} \simeq 0\right)$. Thus, the output power $\mathrm{P}=\mathrm{P}_{\text {gen }}$, as shown in (6).

\section{DYNAMIC BRAKING IMPLEMENT ATION}

Dynamic braking is applied during an emergency to avoid overspeeding-for example, when the connection to the grid is lost during a fault because the system protection disconnects the generator from the grid to protect the generator. When this happens, the balance of power is no longer maintained; thus, the torque equation shown in (4) will be driven by the mechanical torque from the hydrodynamic turbine, and there is no generator torque to counteract and keep the balance in check. Overspeeding can occur in a short time, so either a mechanical brake or electrical dynamic braking must be applied. Dynamic braking has the advantage of having no mechanical contact between a disc brake and brake pad, which for a tidal generator would need to be sealed in a waterproof container, adding to the capital cost and periodic maintenance cost. The implementation of the dynamic braking can be accomplished in several ways. Another advantage of dynamic braking is in the form of an additional protective feature for a power converter of a hydrokinetic generator. Absorbing shortterm power imbalances allows avoiding dangerous overvoltage in the converter DC bus.

\section{A. Braking Resistance $\left(R_{\text {brake }}\right)$}

The equivalent resistance, $\mathrm{R}_{\text {brake, }}$ can be used to illustrate the impact of the size of the braking resistance because the size of the AC resistance determines the effectiveness of the dynamic braking.

The value of the braking resistance that maximizes the braking power can be derived from the Thevenin equivalent from the terminal of the generator:

$$
R_{\text {brake }}=\omega L_{s}-R_{s}
$$

The stator current and the maximum braking power can be computed as follows:

$$
\begin{aligned}
& I_{s}=\frac{E_{p h}}{R_{s}+R_{\text {brake }}+j \omega L_{s}} \\
& P_{\text {max_brake }}=3\left|I_{s}\right|^{2}\left(R_{s}+R_{\text {brake }}\right)=\frac{3 k_{\varphi}^{2} \varphi^{2}}{2 L_{s}} \omega
\end{aligned}
$$

As shown from the equation above, the maximum braking power $\left(\mathrm{P}_{\text {max brake }}\right)$ varies linearly with the rotational speed or frequency. Note that it is common for permanent magnet generators to short circuit its stator windings when parked; however, short-circuiting the terminals of the generator does not produce significant braking power (or torque) when the generator is rotating. In fact, the braking power at short circuit is approximately $16 \mathrm{~kW}$ (losses are converted into heat inside the winding, a major risk for winding insulation failure). In comparison, the $\mathrm{P}_{\max \text { brake }}=110 \mathrm{~kW}$ at $21 \mathrm{~Hz}$, corresponding to $\mathrm{R}_{\text {brake }}=0.74 \mathrm{ohm}$; and at $14 \mathrm{~Hz}$ the $\mathrm{P}_{\text {max brake }}=73 \mathrm{~kW}$, corresponding to $\mathrm{R}_{\text {brake }}=0.47 \mathrm{ohm}$.

\section{B. Implementation of the Braking Resistance}

\section{1) Implementation on the AC Side}

Three-phase resistors can be used to implement AC dynamic braking at the $\mathrm{AC}$ side (also known as a crow-bar solution); however, to make the dynamic braking resistors adjustable, a resistor bank must be used to allow for an adjustable resistance. The implementation on the AC side is shown in Fig. 4, wherein the three-phase resistance is labeled

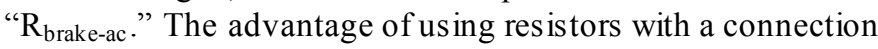
to the AC side is that the device rating (voltage and current) of the diode bridge does not need to be oversized.

\section{2) Implementation on the DC Side}

The implementation on the DC side is shown in Fig. 4, wherein the single resistance is labeled " $R_{\text {brake-dc." The }}$ implementation on the DC side takes advantage of the available DC-DC boost converter currently used to match the generator voltage to the DC bus voltage of the DC-AC inverter. With this arrangement, the $\mathrm{R}_{\text {brake-dc }}$ is varied by adjusting the duty ratio of the pulse-width modulation switch. Note that the resistor must be bypassed during normal operation, thus allowing the power electronics switch, $\mathrm{SW}_{\text {chopper }}$, to function as a DC-DC boost converter. With the DC-side implementation, the device rating of the DC-DC boost converter and the diode bridge must be oversized to allow for overload operation during dynamic braking. 


\section{3) Implementation on Both the DC and AC Sides}

If both the AC-side and DC-side implementations are enabled, the system becomes much simpler, with the AC-side resistance chosen to carry the minimum braking requirement and the DC-side resistance chosen to adjust the braking torque according to the need and thus ensure successful braking. Another advantage is that the device ratings of the diode bridge and the DC-DC boost converter do not need to be oversized to perform the braking operation.

\section{Braking Performance under Variable Speed}

Because the generator is operated in a variable-speed mode, it is convenient to find the braking power at different frequencies. Note that for a permanent magnet generator, the output frequency is proportional to the rotational speed.

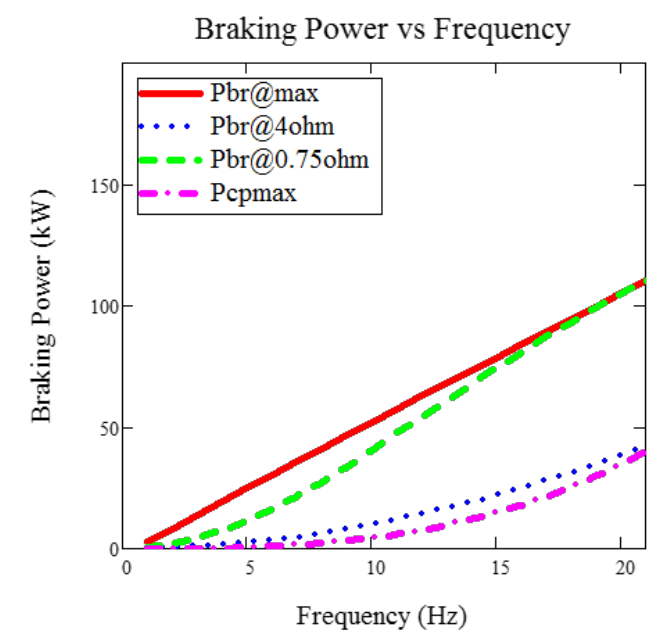

Fig. 5. Braking power vs. $\mathrm{R}_{\text {brake }}$ in variable frequency

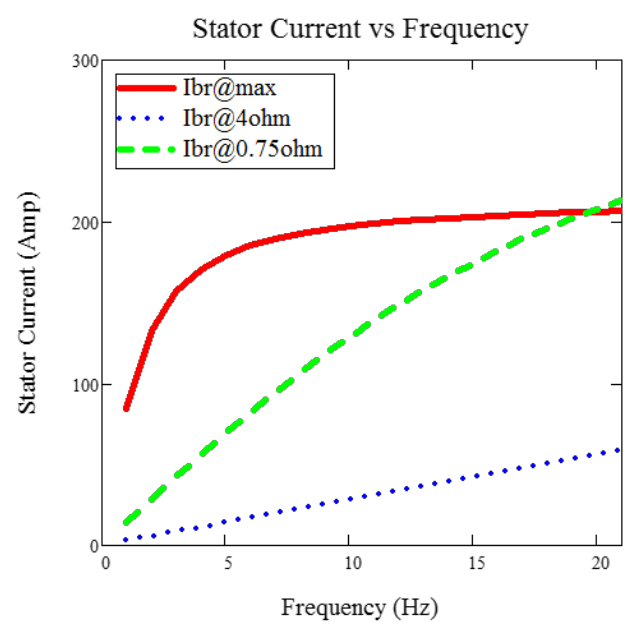

Fig. 6. Stator current magnitude vs. $\mathrm{R}_{\text {brake }}$ at variable frequency

Fig. 5 shows the characteristics of the braking power as a function of the frequency. The corresponding stator current is given in Fig. 6. The output power during normal operation $\left(\mathrm{C}_{\mathrm{pmax}}\right.$ operation) is also given in Fig. 6. Note that for a permanent magnet generator, the output frequency is proportional to the rotational speed. As shown here, the maximum braking power is linearly proportional to the frequency of the generator. To operate in maximum braking power, it is necessary to control the $\mathrm{R}_{\text {brake }}$. This means that with the braking resistance on the AC side, it is not possible to operate in maximum braking power all the time. On the other hand, by controlling the maximum power on the DC side, it is possible to operate more precisely.

As we compare the maximum braking power to the output power for different modes of operation, as shown in Fig. 5, several observations are worth noting:

- The maximum braking power is very high compared to normal output power (maximum $\mathrm{C}_{\mathrm{p}}$ operation; refer to the dashed-dotted pink line in Fig. 5), and several observations should be considered here.

- Operation close to the maximum braking power can also be achieved by applying $R_{\text {brake }}=0.75 \mathrm{ohm}$ (refer to the dashed green line in Fig. 5). This single-value resistance can be implemented on the $\mathrm{AC}$ side with minimal control.

- Operation slightly higher than normal operation $\left(\mathrm{C}_{\mathrm{pmax}}\right.$ operation; refer to the dotted blue line in Fig. 5) can also be achieved by applying $R_{\text {brake }}=4.0 \mathrm{ohm}$. This single-value resistance can be implemented on the AC side with minimal control.

- As shown in Fig. 6, operating at maximum braking power or operating at $R_{\text {brake }}=0.75 \mathrm{ohm}$ produces a very large stator current (much higher than the rated current of $60 \mathrm{~A}$ ), thus overheating of the winding may result if the process of dynamic braking takes longer than expected.

- Based on the above observations, we propose applying a single-value $\mathrm{R}_{\text {brake }}=4.0 \mathrm{ohm}$ implemented as a three-phase constant resistance on the AC side as the braking mechanism. In this way, we can guarantee that at any rotational speed, the braking output power will be larger than the $C_{p \max }$ operation, thus ensuring that the speed control slows down the rotational speed until the generator is reconnected to the grid. As a precaution, we can include additional dynamic braking on the DC side with minimal additional braking resistance, which does not require oversizing the power electronics devices.

\section{CONCLUSION}

This paper explored the dynamic braking of a tidal generator. Basic operation under normal conditions is presented to give the baseline of the fully loaded or rated condition of the tidal generator. The balance of power between the source (turbine) and the sink (generated power to the grid) is an important aspect of the speed control. Understanding this balance of power is the key to designing a successful dynamic braking system. The maximum braking power is derived as a function of the rotational speed to explore the possible electrical output power that can be extracted from the generator. Similarly, the maximum performance coefficient of the turbine is used during normal operation; thus, the 
maximum turbine hydrodynamic output power is also derived as a function of the rotational speed. Knowing the envelope of the operating ranges of both the turbine and the generator, we can design the control strategy so that the generator will be controlled to maximize the efficiency of the turbine $\left(\mathrm{C}_{\mathrm{pmax}}\right.$ operation) during normal conditions. It will be operated in the dynamic braking mode during emergencies when the generator is disconnected from the grid because of a fault or other disturbance.

From our investigation, we proposed a simple dynamic braking system with AC-side dynamic braking implemented using a single-step, three-phase braking resistor. The size of the braking resistor is computed so that the generator will slightly generate electrical output power above $\mathrm{C}_{\mathrm{pmax}}$ operation. This control method will force the turbine to stall, and the rotational speed will decrease to zero. As a backup and to ensure successful dynamic braking, DC dynamic braking is also included to provide additional power. This DC dynamic braking can be implemented by utilizing the existing DC-DC boost converter with a small modification.

\section{ACKNOWLEDGMENT}

This work was supported by the U.S. Department of Energy under Contract No. DE-AC36-08-GO28308 with the National Renewable Energy Laboratory.

\section{REFERENCES}

[1] S. E. Ben Elghali, M. E. H. Benbouzid, and J. F. Charpentier, "Marine tidal current electric power generation technology: State of the art and current status," in Proc. 2007 IEEE International Electric Machines \& Drives Conference (IEMDC '07), May 3-5 2007, Antalya, Turkey.

[2] E. Muljadi and Y. H. Yu, "Review of marine hydrokinetic power generation and power plant," Electric Power Components and Systems, vol. 43, no 12, 2015, Special Issue: Renewable Energy Devices and Systems - State-of-the-Art and Future Trends; Frede Blaabjerg - Guest Editor-in-Chief; and Dan M. Ionel-Editor in Chief; Taylor \& Francis.

[3] Y. Kyozuka and K. Ogawa, "Tidal current power generation making use of a bridge pier," presented at OCEANS 2006-Asia Pacific Conference, May 16-19, 2007, Singapore.

[4] K. S. Lee and L. Y. Seng, "Preliminary investigation of the potential of harnessing tidal energy for electricity generation in Malaysia," in Proc. 2008 IEEE Transmission and Distribution Conf. and Expo. (IEEE PES T\&D), April 21-24, 2008, Chicago, IL

[5] M. Liu, W. Li, R. Billinton, C. Wang, and J. Yu, "Probabilistic modeling of tidal power generation," in Proc. 2015 IEEE Power \& Energy Society General Meeting (IEEE PES GM), July 26-30, 2015, Denver, Colorado.

[6] J. S. Choi, R. G. Jeong, J. H. Shin, C. K. Kim, and Y. S. Kim, "New control method of maximum power point tracking for tidal energy generation system," in Proc. 2007 International Conference on Electrical Machines and Systems, Oct. 8-11, 2007, Seoul, Korea.

[7] J. Hao, M. Chen, X. Duan, and Y. Luo, "Portable maximum power tracking method of tidal generation system based on output slope characteristics," in Proc. 201433 rd Chinese Control Conference, July 28-30, 2014, Nanjing, China

[8] J. Fang, C. Heising, V. Staudt, and A. Steimel," Permanent-magnet synchronous machine model for urban transport applications,"presented at the 12th International Conference on Optimization of Electrical and Electronic Equipment (OPTIM 2010), May 20-22, 2010, Brasov, Romania.
[9] S. S. Kurupu, K. B. Ariyur, and N. A. Kulatunga, "Electric machine vs. mechanical brakes for traction control with real time ex tremum seeking control," presented at the 40th Annual Conference of the IEEE Industrial Electronics Society (IECON 2014), Oct. 29,2014-Nov. 1 2014, Dallas, Texas.

[10] A. M. Omekanda, B. Lequesne, H. Klode, S. Gopalakrishnan, and I. Husain, "Switched reluctance and permanent magnet brushless motors in highly dynamic situations: A comparison in the context of electric brakes," IEEE Industry Applications Magazine, vol. 15, no. 4, July-Aug 2009 